\title{
Atmospheric blocking anomalies as the synoptic precursors prior to the induced earthquakes: a new climatic conceptual model
}

\author{
M. R. Mansouri Daneshvar - T. Tavousi • \\ M. Khosravi
}

Received: 6 June 2014/Revised: 12 November 2014/ Accepted: 7 December 2014/Published online: 16 December 2014

(C) Islamic Azad University (IAU) 2014

\begin{abstract}
Blocking as an interruption of the climatological storm tracks means an extreme disturbance in the synoptic scale of atmospheric circulation. In this study, we aimed to describe the main role of atmospheric blocking on the earthquake prediction in the southern Iran. We gathered the subjective evidences of a block generation during April 5-9, 2013, which was clearly identified by anomalous data of geopotential height, air temperature, vertical velocity, rainfall rate and latent heat flux. Analysis of geopotential heights at the 500 and 300 $\mathrm{hPa}$ levels revealed that there was a dipole split-flow block with associated of a remarkable low-pressure anomaly $(-76 \mathrm{~m})$, which has established over southern Iran during April 5-9, 2013. This low pressure into three temporal sequences has influenced three epicenters of upcoming earthquake swarms in south parts of Iran during April and May 2013. Hence, we detected an atmosphericlithospheric cycle as a climatic conceptual model that describes the chain of the blocking-associated rainfall, preceding rainfall-triggered seismic stress, cyclogenesis, thunderstorm and subsequent stress-induced seismicity. We claimed that the blocking-associated anomalies together with the persistence of low pressure could be the earthquake precursors within 3-33 days before the main seismic shocks in Iran.
\end{abstract}

M. R. Mansouri Daneshvar $(\bowtie) \cdot$ T. Tavousi · M. Khosravi Department of Physical Geography and Climatology,

University of Sistan and Baluchestan,

Zahedan, Iran

e-mail: mrm_daneshvar2012@yahoo.com
Keywords Atmospheric-lithospheric cycle · Blockingassociated anomaly $\cdot$ Earthquake swarms $\cdot$ Geopotential heights $\cdot$ Rainfall-triggered stress

\section{Introduction}

The recent research in earthquake prediction depends on the analysis of the specific variations in the lithosphere and atmosphere associated with upcoming earthquakes. Therefore, theoretical and experimental studies explicitly demonstrated the ability of remote sensing technologies to identify the geophysical earthquake precursors, which appear several days before the seismic stress over the seismically active areas (Pulinets 2006). Synchronism of the precursors prior to the earthquakes, which can be accounted in earthquake prediction, has been registered using different methods in different fields. In this regard, there is a geophysical list of precursors including of radon migration, air ionization, latent heat release, changes in atmospheric electricity, thermodynamic processes leading to outgoing long-wave radiation, changes in surface air temperature, relative humidity, air pressure, earthquake clouds formation, coupling with rainfall, ionosphere and magnetosphere effects, radio wave propagation and generation of electromagnetic emissions (Pulinets 2011). Recent development of lithosphere-atmosphere-ionosphere coupling (LAIC) model has demonstrated the geophysical anomalies within the few days before the seismic shock (Pulinets and Ouzounov 2011). However, the LAIC model focuses just on fault activation and gas migration as the main source of precursor's chain without climatologic attitude. Now, we can present a new climatic conceptual model. In this regard, we can claim that the atmospheric blocking-associated anomaly is the main triggering chain 
of lithospheric gas exhaustion, stress-induced seismicity and subsequent atmospheric anomalies. These reactions are tracked along a systematic feedback mechanism between atmosphere, lithosphere and atmosphere. Recently, Iaffaldano et al. (2011) have defined the continuous feedback mechanisms between lithospheric motions and atmospheric dynamics, where at times one controls the other and vice versa. One of the atmospheric dynamics is atmospheric blocking that plays an important role in the mid-latitude climate variability and anomalous extreme climate (Sillmann and Croci-Maspoli 2009). Atmospheric blocking is a weather phenomenon where the strength of the westerly circulation is temporarily reduced (Rex 1950). When the stationarity and the persistence of blocking is combined with the anomalous-flow conditions, it can be into an important source of abnormal weather (Trigo et al. 2004; Cattiaux et al. 2010; Sillmann et al. 2011; Buehler et al. 2011). According to published literature, the blocking events arise from Rossby waves, which extend across the mean westerly troughs and then a large-scale ridge locks with the smaller scale flows. The blocking systems are identified using anomalies of the geopotential height at 500 $\mathrm{hPa}$ together with atmospheric anomalies of rainfall rate, surface temperature, vertical velocity, latent heat flux, specific humidity and surface pressure. The abnormal waves are mainly due to internal atmospheric dynamical processes that produce and maintain a blocking event (Dole et al. 2011). From the other side, the aforementioned atmospheric anomalous data are widely applied as the earthquake precursors in the scientific research. The main aim of the present study was to expose an atmosphericlithospheric cycle as a climatic conceptual model, which describes the chain of blocking-associated anomalies and following stress-induced seismicity. Hence, the new hypothesis in the present study relates to the role of associated-blocking anomalies as the synoptic precursors of induced earthquakes. To examine the assumption we investigated, the three recent seismic swarms comprised three major earthquakes $(M>6)$ in the southern Iran.

\section{Materials and methods}

Study area

The extracted data via (http://earthquake.usgs.gov/ earthquakes) revealed that about 200 earthquakes $(M>3)$ have occurred in the Middle East within April and May 2013, which have been regulated along five longitudes as shown in Table 1. Meanwhile, about 150 earthquakes have shaken the south parts of Iran, along the longitudes of 50 and 60, on the pattern of three swarm clusters, which are considered in the
Table 1 The list of earthquakes $(M>3)$ in the Middle East during April and May 2013 along five longitudes

\begin{tabular}{|c|c|c|c|c|c|c|}
\hline No. & Date & $30 \mathrm{E}$ & $40 \mathrm{E}$ & $50 \mathrm{E}$ & $60 \mathrm{E}$ & $70 \mathrm{E}$ \\
\hline 1 & $2013 / 04 / 01$ & 1 & & & & \\
\hline 2 & $2013 / 04 / 04$ & & & & & 3 \\
\hline 3 & $2013 / 04 / 05$ & 1 & & & & 1 \\
\hline 4 & $2013 / 04 / 07$ & 1 & & 1 & & \\
\hline 5 & $2013 / 04 / 09$ & & & 27 & & \\
\hline 6 & $2013 / 04 / 10$ & & & 14 & & \\
\hline 7 & $2013 / 04 / 11$ & & & 3 & & \\
\hline 8 & $2013 / 04 / 12$ & & & 2 & & 1 \\
\hline 9 & $2013 / 04 / 13$ & & & 3 & & \\
\hline 10 & $2013 / 04 / 14$ & & & 3 & & \\
\hline 11 & 2013/04/16 & & & 2 & 4 & \\
\hline 12 & $2013 / 04 / 17$ & & & & 3 & 1 \\
\hline 13 & $2013 / 04 / 18$ & & & 2 & & \\
\hline 14 & 2013/04/19 & & & 3 & & 2 \\
\hline 15 & $2013 / 04 / 20$ & & 1 & & 1 & \\
\hline 16 & $2013 / 04 / 21$ & 1 & & & & 1 \\
\hline 17 & $2013 / 04 / 22$ & & & 1 & & \\
\hline 18 & $2013 / 04 / 23$ & & & & 1 & \\
\hline 19 & $2013 / 04 / 24$ & & & 2 & & 2 \\
\hline 20 & $2013 / 04 / 25$ & & 2 & & & \\
\hline 21 & $2013 / 04 / 26$ & & & 2 & & \\
\hline 22 & $2013 / 04 / 27$ & & & & & 1 \\
\hline 23 & $2013 / 04 / 28$ & 1 & & 2 & & \\
\hline 24 & $2013 / 04 / 30$ & & & 2 & 1 & 4 \\
\hline 25 & $2013 / 05 / 01$ & & & 2 & 1 & 2 \\
\hline 26 & $2013 / 05 / 02$ & & & 2 & & \\
\hline 27 & $2013 / 05 / 03$ & & & & & 1 \\
\hline 28 & $2013 / 05 / 04$ & & & 3 & & \\
\hline 29 & $2013 / 05 / 06$ & & & 1 & & \\
\hline 30 & $2013 / 05 / 07$ & & & 2 & & 1 \\
\hline 31 & 2013/05/09 & & & & 2 & \\
\hline 32 & 2013/05/11 & & & 1 & 28 & 1 \\
\hline 33 & 2013/05/12 & & & 1 & 14 & 1 \\
\hline 34 & 2013/05/13 & & & 1 & 1 & \\
\hline 35 & $2013 / 05 / 14$ & & & & 1 & 4 \\
\hline 36 & $2013 / 05 / 15$ & & & & 1 & 1 \\
\hline 37 & $2013 / 05 / 16$ & 2 & & & & \\
\hline 38 & $2013 / 05 / 18$ & & & & 3 & \\
\hline 39 & $2013 / 05 / 20$ & 1 & & & 2 & 1 \\
\hline 40 & $2013 / 05 / 21$ & & & 1 & 1 & \\
\hline 41 & $2013 / 05 / 22$ & 1 & & & & 2 \\
\hline 42 & $2013 / 05 / 23$ & & & 2 & & \\
\hline 43 & $2013 / 05 / 24$ & & & 1 & & 3 \\
\hline 44 & $2013 / 05 / 26$ & & & & & 1 \\
\hline 45 & $2013 / 05 / 29$ & 1 & & & 1 & \\
\hline \multirow[t]{2}{*}{46} & $2013 / 05 / 31$ & & & 1 & 1 & 1 \\
\hline & Sum & 10 & 3 & 87 & 66 & 35 \\
\hline
\end{tabular}


Fig. 1 The seismicity of the Middle East on April and May 2013 and three seismic swarms in the south parts of Iran including of 1 Bushehr, 2 Saravan and $\mathbf{3}$ Angohran earthquakes, the stars are pointed to epicenter locations of the major earthquakes with $M>6$
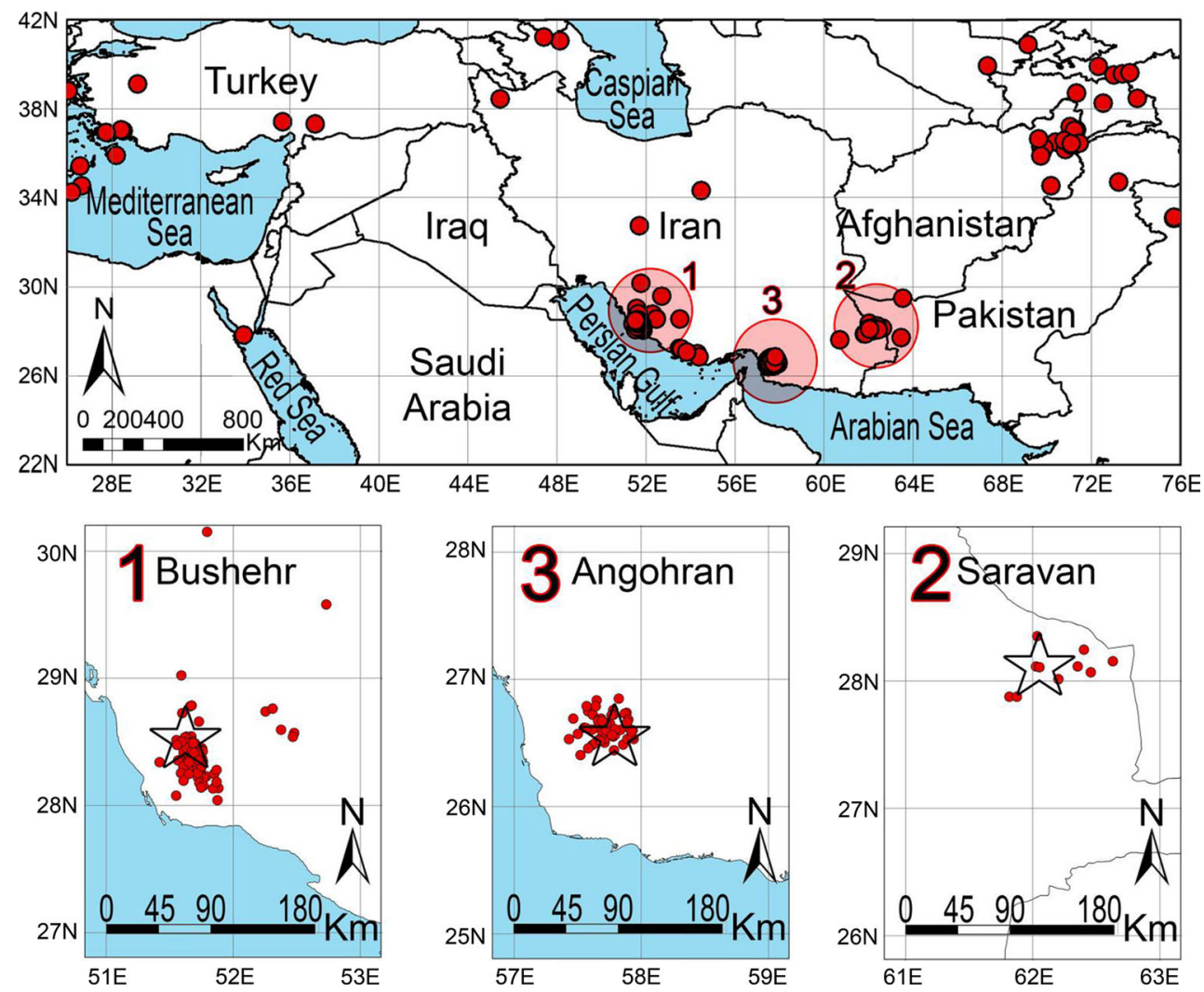

present study (Fig. 1). The M6.4 Bushehr earthquake with hypocenter depth of $10 \mathrm{~km}$ and epicenter location of $28.5 \mathrm{~N}$ and 51.6 E occurred on April 09, 2013. This earthquake a before-shock with magnitude of $M=4.1$ and 72 aftershocks with magnitudes from $M=3.7$ to 5.4 has produced over the 28-29 $\mathrm{N}$ latitude and 51-52 E longitude within April 07 to May 31, 2013. The M7.8 Saravan earthquake with hypocenter depth of $82 \mathrm{~km}$ and epicenter location of $28.1 \mathrm{~N}$ and 62.1 occurred on April 16, 2013. This earthquake some 12 after-shocks with magnitudes from $M=4.0$ to 5.6 has produced over the 28-29 N latitude and 62-63 E longitude within April 16 to May 29, 2013. The M6.1 Angohran earthquake with hypocenter depth of $15 \mathrm{~km}$ and epicenter location of $26.5 \mathrm{~N}$ and 57.7 occurred on May 11, 2013. This earthquake a before-shock with magnitude of $M=4.9$ and 72 after-shocks with magnitudes from $M=3.9$ to 5.5 has produced over the 26-27 N latitude and 57-58 E longitude during the May 09-31, 2013 (USGS 2013; EMSC 2013). Therefore, the geological setting of three aforementioned epicenter locations in this study is varied from Zagros sedimentary basin in west to Makran subduction zone in east. These areas are the active seismological regions in the Middle East. The Makran subduction zone is the surface expression of active subduction of the Arabia plate beneath the Eurasia plate, and the Zagros basin is a complex collision of the Arabia and Eurasia plates with the fold and thrust belt (Mansouri Daneshvar et al. 2014b).

Fundamental theories in atmosphere-lithosphere relation

\section{Rainfall-triggered seismicity}

Potential trigger mechanisms of earthquakes may involve atmospheric temperature, pressure and rainfall (Matthews et al. 2009). Earthquakes occur when the stresses acting on rock across the fault exceed some critical value so that failure occurs. Fluids influence this failure by changing stress. In this regard, both natural and engineering processes that can increase pore pressures and hence influence seismicity (Wang and Manga 2009). A correlation between precipitation and earthquakes (Jiménez and Garcia-Fernández 2000; Ogasawara et al. 2002; Hainzl et al. 2006; Kraft et al. 2006; Husen et al. 2007) supports the idea that pore pressure changes caused by rainfall recharge can influence seismicity. The distinctive signature of earthquakes triggered by pore pressure stress is a spatial migration of swarm epicenters. Tadokoro et al. (2000) have 
identified a migration of seismicity along a fault zone following water loading. Shapiro et al. (2006) document a similar migration of seismicity over a fault zone. Recently, Muço (2013) has presented evidence that seismic activity in North American tectonic zones can be triggered clearly with the effects of abundant rainfall. For the separate earthquakes in Europe, Miller (2008) has showed that the unambiguous rainfall-triggered seismicity and the seismicity rates increase after the catastrophic storms. Such effects can increase tectonic stress, which exceeds the rainfall amounts when an earthquake occurs. Previously was pointed the role of water on the generation of intraplate seismicity by Costain et al. (1987). Hainzl et al. (2006) have found the clear evidence that pore pressure changes induced by rainfall are able to trigger earthquake activity even at surficial depth via the mechanism of fluid diffusion. However, Kraft et al. (2006) have revealed the two cases of earthquake swarms that follow heavy rainfall events. In the shallower focal depths, induced earthquakes will be caused by stresses in pore pressure changes. Nevertheless, in deep focal depths, it is dominantly caused by dynamic stresses with the passage of the natural seismic waves (Wang and Manga 2009). Therefore, in profound seismicity, Mastin (1994) had observed an increase in explosive tephra emissions at Mount St. Helens within 2-15 days after rainfall storms. Using minute-by-minute records of rainfall and seismic activity, Matthews et al. (2002) have observed a volcano-seismic response within $2 \mathrm{~h}$ after rainfall. Analysis of long-term time series have shown that rainfall can also trigger the volcanic seismicity over several months at least (Neuberg 2000; Violette et al. 2001; Mason et al. 2004).

\section{Cyclogenesis and thunderstorm}

In the case of the earthquakes, some powerful thunderstorm activities have been observed prior to the major earthquakes (Freund 2003). Gousheva et al. (2008) have exhibited that the anomalies of atmospheric responses such as thunderstorms can be observed over the epicenters, approximately 5 days before the earthquake event. In a thunderstorm, the bottom part of the cloud layer with large aerosol particles will be charged negatively and the top part with small particles positively (Liperovsky et al. 2005). Then, it will be a geomagnetic disturbance as reverse electric direction of the natural condition (Pulinets and Ouzounov 2011). Ondoh (2009) for the M7.2 earthquake in Japan, has shown that a low atmospheric pressure center was passing over the Japan Sea, upward anomalous clouds, strong lightning discharges and intense radio noises in associated with terrestrial gas emanations had occurred around the cold front, 1 week prior to the main shock on January 17, 1995. Liu et al. (2004) have observed the thunderstorm occurrences, approximately 10 days prior to the M7.3 and M9.3 earthquakes on September 21, 1999, in Taiwan and on December 26, 2004, earthquake in Indonesia, respectively. In recent M7.8 north Saravan earthquake in Iran, Mansouri Daneshvar et al. (2014a) have believed that the presence of a powerful thunderstorm has played a main role in triggering the chain of atmospheric anomalies, ascending air turbulence, abnormal cloud circulation and the significant reduction in air pressure, 1 week prior to the main shock on April 16, 2013. Pulinets and Ouzounov (2011) have revealed that the thunderstorm activity can trigger the global electric circuit (GEC) and total electric content (TEC). On this basis, for the M7.8 north Saravan earthquake, the seismo-ionospheric disturbances of TEC have been indicated about 1 week prior to the earthquake (Pundhir et al. 2014).

\section{Data preparation}

Atmospheric blocking objectively has been investigated based on a set of criteria (e.g., Tibaldi and Molteni 1990; Wiedenmann et al. 2002; Pelly and Hoskins 2003; Barriopedro et al. 2006). However, subjective analysis has been probed based on synoptic scale experience and a set of geopotential height anomalies at $500 \mathrm{hPa}$ (e.g., Lejenäs and Økland 1983; Dole and Gordon 1983; Scherrer et al. 2006). In this study, we applied the subjective method in order to investigate of blocking evidence. For the subjective detection of blocking events and its persistency, we have used the daily $\mathrm{NOAA}^{1} / \mathrm{NCEP}^{2}$ reanalysis to composite data including the atmospheric variations of geopotential height at level $500 \mathrm{hPa}$, air temperature and vertical velocity (omega) based on the normal climatology period (1981-2010) via (http://www.esrl.noaa.gov/psd/data/gridded). Therefore, to detect temporal anomalous records, we derived daily climatic time series data during April and May 2013 for rainfall ratio and surface latent heat flux (SLHF) according to $\mathrm{NASA}^{3} /$ Giovanni $^{4}$ remote sensing data via (http://www. disc.sci.gsfc.nasa.gov/giovanni).

\footnotetext{
${ }^{1}$ National Oceanic and Atmospheric Administration (http://www. noaa.gov).

2 National Centers for Environmental Prediction.

${ }^{3}$ National Aeronautics and Space Administration (http://www.nasa. gov).

${ }^{4}$ Geospatial Interactive Online Visualization and Analysis Infrastructure (Giovanni) is a Web-based application developed by Goddard Earth Sciences Data and Information Services Center (GES DISC) that provides an intuitive way to visualize, analyze, and access of Earth science remote sensing data.
} 


\section{Results and discussion}

Synoptic analysis

The chain of several major earthquake and seismic swarms in Middle East and particularly in southern Iran were observed on April and May 2013, when some anomalies in atmospheric data were recorded as synoptic extremes. During April and based on the $500 \mathrm{hPa}$ (300 hPa) level heights, a remarkably abnormal low pressure persisted over southern Iran, with a minimum anomaly of $-30 \mathrm{~m}$ $(-40 \mathrm{~m})$ (Fig. 2). This low-pressure anomaly is related to abnormal variation of wave in the Jet stream over the Northern Hemisphere. In general, it has been confirmed that North Hemisphere blocking occurred most frequently over the Pacific and Atlantic Ocean basins (Lejenäs and Økland 1983; Huang et al. 2004). Nevertheless, Dole and Gordon (1983) had identified a distinct block formation region over Eastern Europe and Western Asian continents. In this regard was gained a blocking archive based on Northern Hemisphere blocking events during April and May 2013 via (http://weather.missouri.edu/gcc) as shown in Table 2. The table indicates a list of about 15 blocking events over the Pacific, Atlantic and continental territories of NH. One of the aforementioned continental events is a blocking during April 2-8, 2013, that has influenced the Middle East region in eastern longitude of $60^{\circ}$. Hence, the blocking episode is exposed during the early days of April 2013. Analysis of mean 5-day geopotential height at the 500 and $300 \mathrm{hPa}$ levels via (http://www.esrl.noaa.gov/psd/ data/gridded) revealed that there was a dipole split-flow block during April 5-9, 2013 (Fig. 3a, b). It was associated with a low pressure, which established by minimum negative anomaly of $-75 \mathrm{~m}$ over the south parts of Iran. Based on the $500 \mathrm{hPa}(300 \mathrm{hPa})$ level heights, the high pressure extended over Central Asia and Kazakhstan with a maximum positive anomaly of $+150 \mathrm{~m}(+225 \mathrm{~m})$ (Fig. 3c, d). The effects of the aforementioned block over the southern Iran could be divided into three sequences. The first sequence on April 6-7 was the period of extreme lowpressure wave, which has influenced the southwest parts of Iran with associated rainfall and cyclogenesis events. According to NOAA/NCEP reanalysis data, this sequence is detected by composite mean and anomalies of $500 \mathrm{hPa}$ geopotential height, air temperature and vertical velocity upon the Bushehr epicenter (Fig. 4a-d). Both the temperature and $500 \mathrm{hPa}$ vertical motion fields revealed the occurrence of cold temperature and upward vertical motion in a deep trough over the southwestern Iran. This trough

Table 2 The list of blocking events in North Hemisphere during April and May 2013

\begin{tabular}{llllcc}
\hline No. & Territory & $\begin{array}{l}\text { Began } \\
\text { date }\end{array}$ & $\begin{array}{l}\text { Ended } \\
\text { date }\end{array}$ & $\begin{array}{l}\text { Persisted } \\
\text { days }\end{array}$ & $\begin{array}{l}\text { Genesis } \\
\text { longitude } \\
\left({ }^{\circ}\right)\end{array}$ \\
\hline 1 & Atlantic & $2013 / 03 / 31$ & $2013 / 04 / 05$ & 5 & -30 \\
2 & Continent & $2013 / 04 / 02$ & $2013 / 04 / 08$ & 6 & 60 \\
3 & Pacific & $2013 / 04 / 08$ & $2013 / 04 / 18$ & 10 & 160 \\
4 & Pacific & $2013 / 04 / 11$ & $2013 / 04 / 14$ & 33 & -140 \\
5 & Pacific & $2013 / 04 / 24$ & $2013 / 05 / 07$ & 13 & 180 \\
6 & Atlantic & $2013 / 04 / 25$ & $2013 / 05 / 01$ & 6 & -50 \\
7 & Atlantic & $2013 / 04 / 27$ & $2013 / 05 / 07$ & 10 & 30 \\
8 & Continent & $2013 / 05 / 01$ & $2013 / 05 / 09$ & 8 & -80 \\
9 & Continent & $2013 / 05 / 03$ & $2013 / 05 / 08$ & 5 & 90 \\
10 & Atlantic & $2013 / 05 / 06$ & $2013 / 05 / 23$ & 17 & 30 \\
11 & Pacific & $2013 / 05 / 10$ & $2013 / 05 / 15$ & 5 & 150 \\
12 & Atlantic & $2013 / 05 / 11$ & $2013 / 05 / 29$ & 18 & -30 \\
13 & Continent & $2013 / 05 / 18$ & $2013 / 05 / 25$ & 7 & 130 \\
14 & Pacific & $2013 / 05 / 21$ & $2013 / 05 / 28$ & 7 & -110 \\
15 & Continent & $2013 / 05 / 25$ & $2013 / 06 / 07$ & 13 & 50 \\
\hline
\end{tabular}

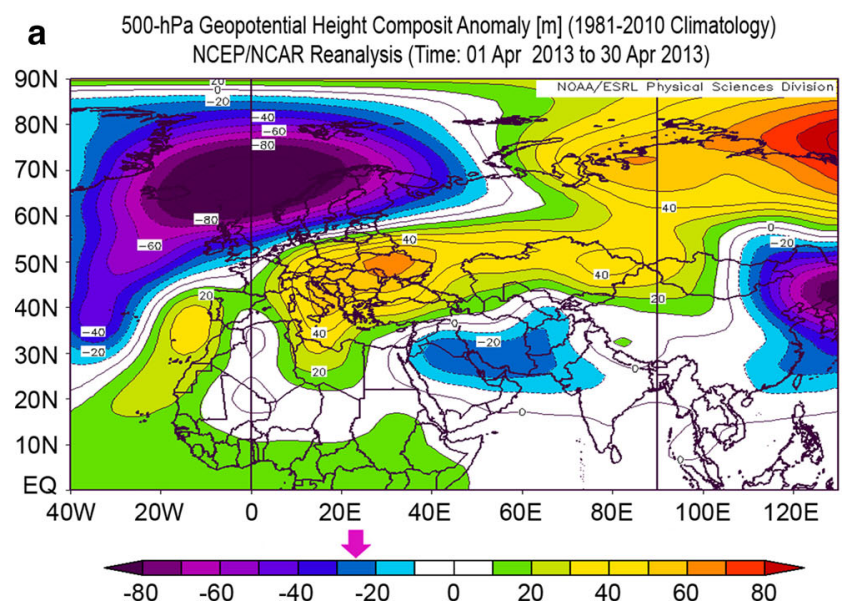

Fig. 2 Remarkable low-geopotential height anomaly over southern Iran at a $500 \mathrm{hPa}$ and b $300 \mathrm{hPa}$ levels during April 2013 

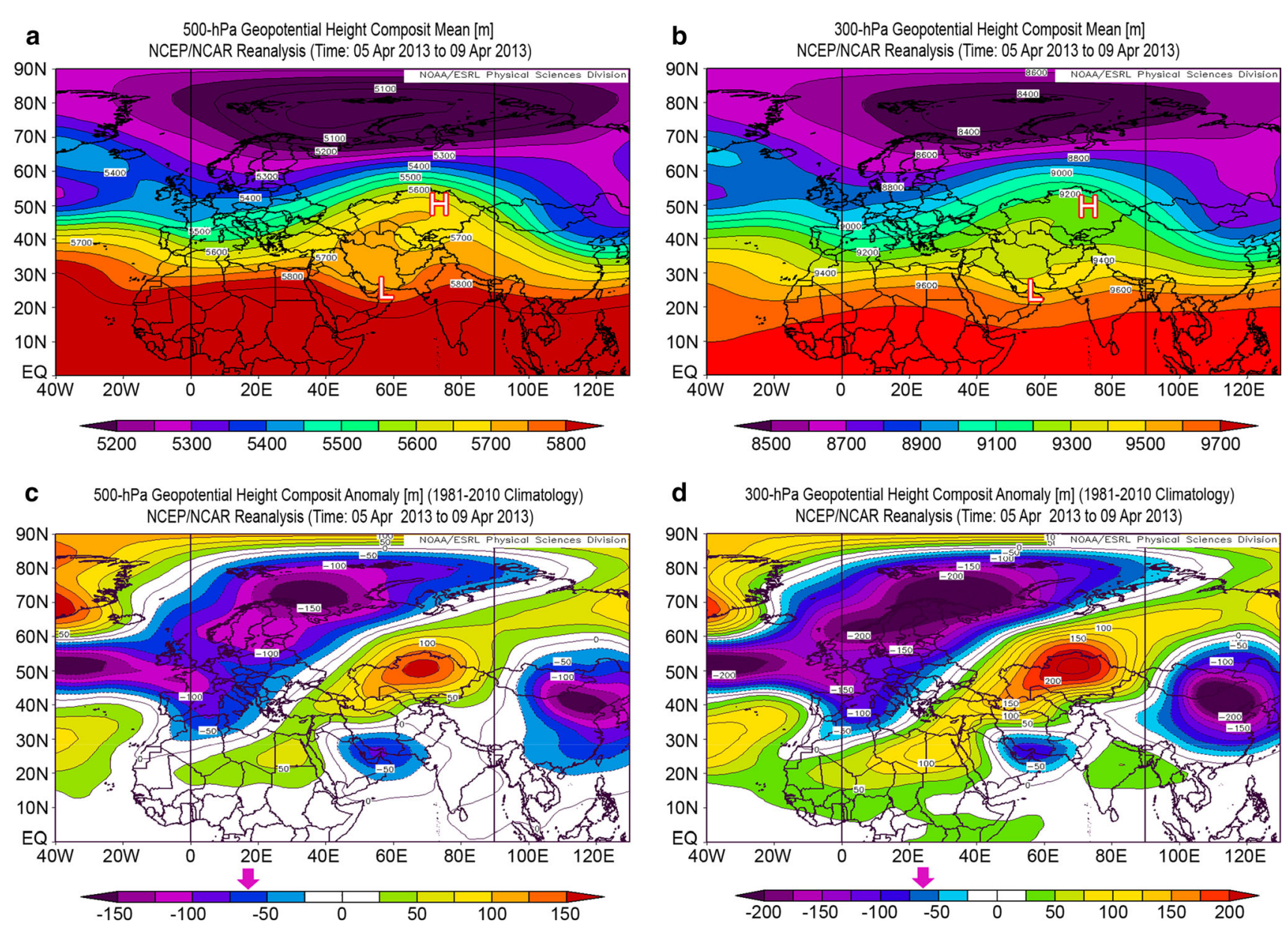

Fig. 3 Geopotential height means at a $500 \mathrm{hPa}$ and b $300 \mathrm{hPa}$ levels and geopotential height anomalies at c $500 \mathrm{hPa}$ and d $300 \mathrm{hPa}$ levels during April 5-9, 2013

wave is caused to air disturbance with moist and cold condition, severe rainfall rate and suddenly enhanced SLHF (Fig. 4e, f). Likewise, the second and third sequences on April 7-8 and April 8-9, 2013, were the periods of low-pressure wave, which have influenced the south parts of Iran with associated extreme rainfall events. These sequences are detected by composite mean and anomalies of $500 \mathrm{hPa}$ level height, air temperature and omega together with abnormal rainfall rate and SLHF upon the Angohran and Saravan epicenters, respectively (Figs. 5, 6). The results revealed that a dipole block was persisted over the Middle East and was associated with a strong westerly air current aloft over southern Iran within 5-9 April 2013. The splitting of westerly winds into two branches occurred over the Iran, the first branch passed toward the north of Iran, Caspian Sea and Central Asia, while the second extended to the south toward Red Sea and Persian Gulf. This equatorward branch of the flow could have received enough water vapor from the sea surface and then deposited this moisture in the form of rain over southern Iran.

Temporal data and time series

According to NASA/Giovanni reanalysis data, the time series for rainfall rate and SLHF is revealed the sudden enhancement of abnormal rainfall and SLHF over three epicenter locations during April 5-9, 2013 (Fig. 7). This figure clearly illustrates the block structure associating with the extreme rainfall events and SLHF. According to the temporal data, the accumulated rainfall was more than 105,55 and $85 \mathrm{~mm}$ during the block presence over the earthquake epicenter locations of Bushehr, Saravan and Angohran, respectively. In addition, the maximum values of surface latent heat flux are occurred about 390, 370 and $440 \mathrm{~W} \mathrm{~m}^{-2}$ during the block presence for earthquake epicenter locations of Bushehr, Saravan and Angohran, respectively. This figure indicates that the sudden 

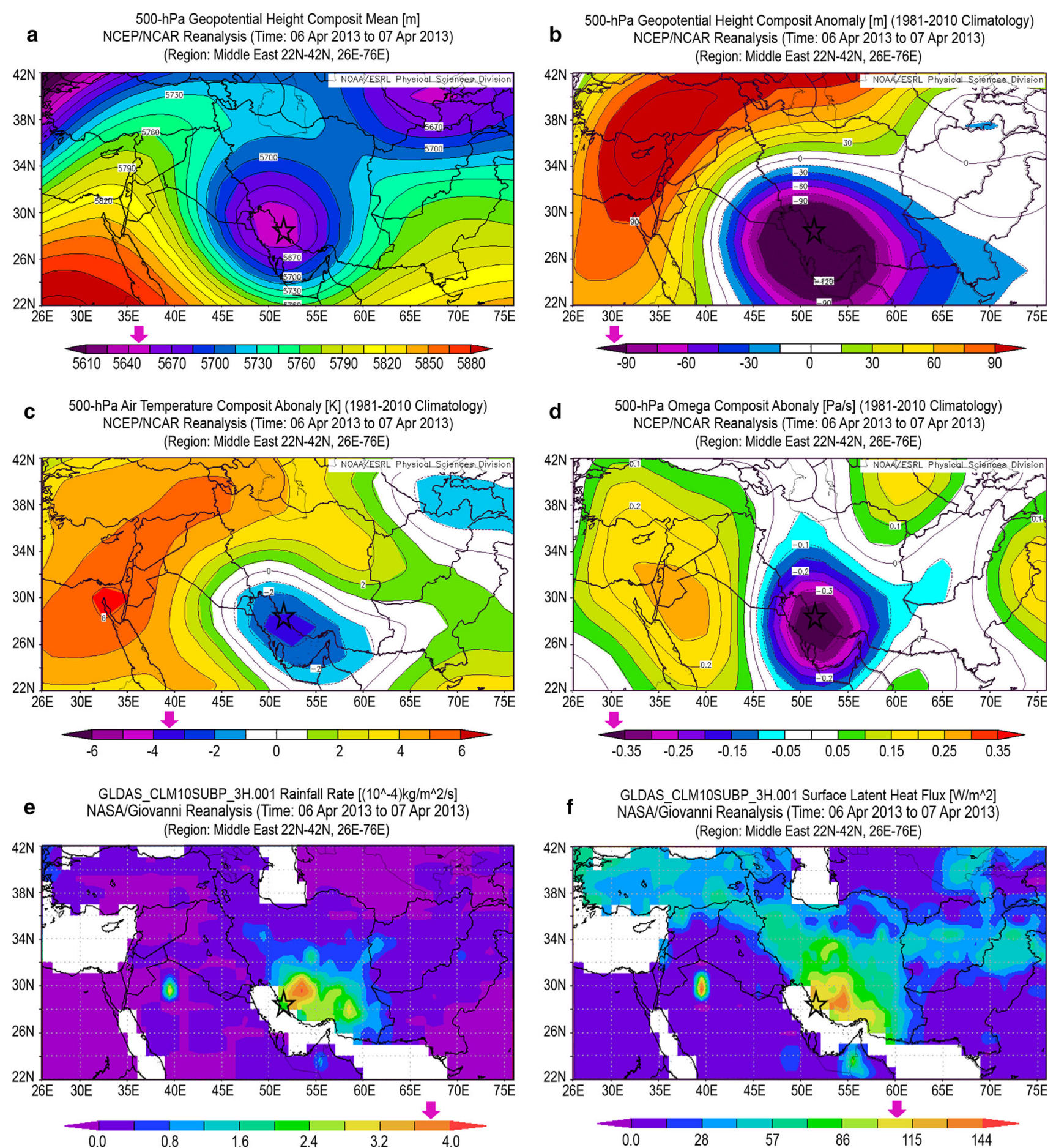

Fig. $4500 \mathrm{hPa}$ composite NCEP/NCAR reanalysis maps of a geopotential height mean, b geopotential height anomaly, $\mathbf{c}$ air temperature anomaly and d omega anomaly, and surface NASA/Giovanni

enhancement of rainfall and SLHF is induced by the blocking event prior to the upcoming seismic shocks. According to the earthquake list provided by USGS during April and May 2013, the frequencies of the

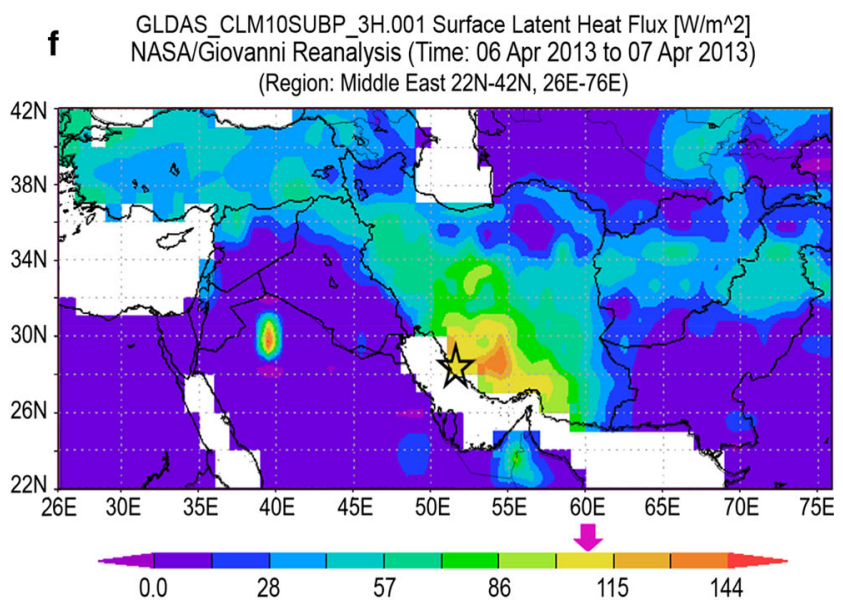

reanalysis maps of $\mathbf{e}$ rainfall rate and $\mathbf{f}$ latent heat flux during April 6-7, 2013 upon the Bushehr epicenter

earthquakes were generated for each swarm in the aforementioned Fig. 7. Therefore, the figure confirms that the lag seismicity of the study area may be partially caused by blocking-associated rainfall and SLHF prior to 


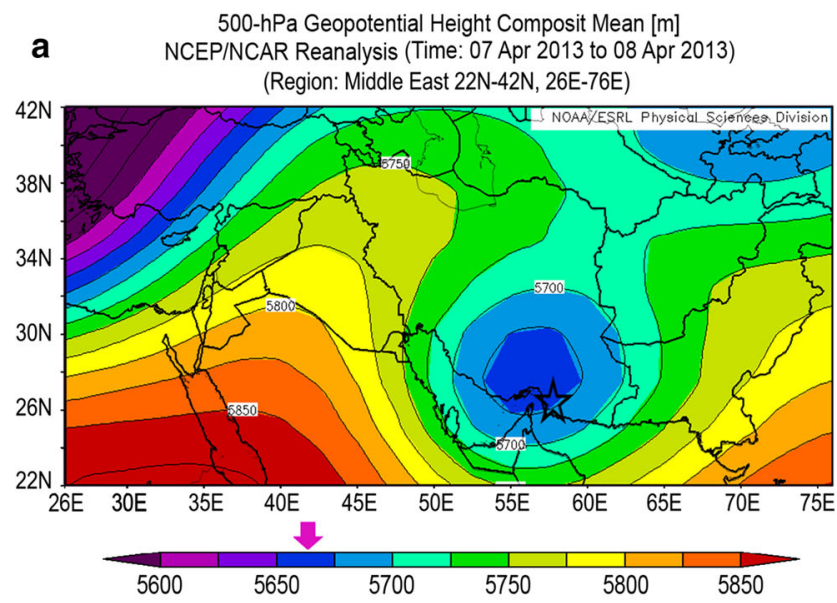

500-hPa Air Temperature Composit Abonaly [K] (1981-2010 Climatology) NCEP/NCAR Reanalysis (Time: 07 Apr 2013 to 08 Apr 2013) (Region: Middle East 22N-42N, 26E-76E)

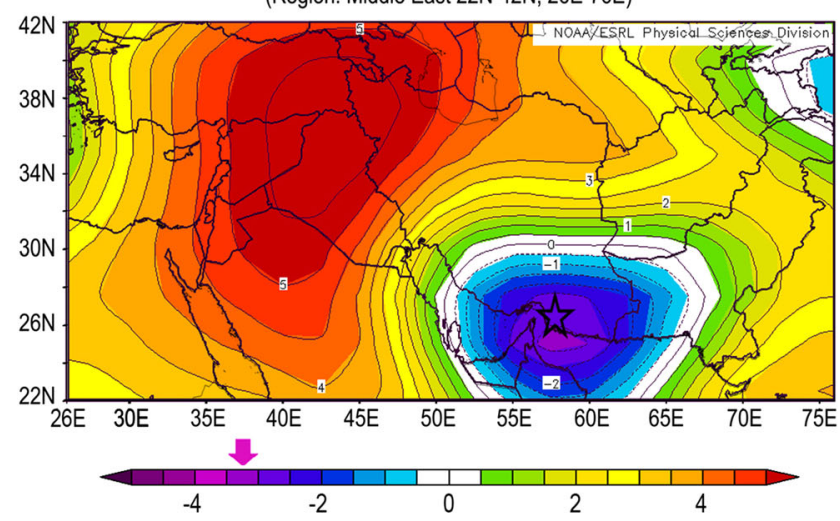

e GLDAS_CLM10SUBP_3H.001 Rainfall Rate [(10^-4) $\left.\mathrm{kg} / \mathrm{m}^{\wedge} 2 / \mathrm{s}\right]$ NASA/Giovanni Reanalysis (Time: 07 Apr 2013 to 08 Apr 2013) (Region: Middle East 22N-42N, 26E-76E)

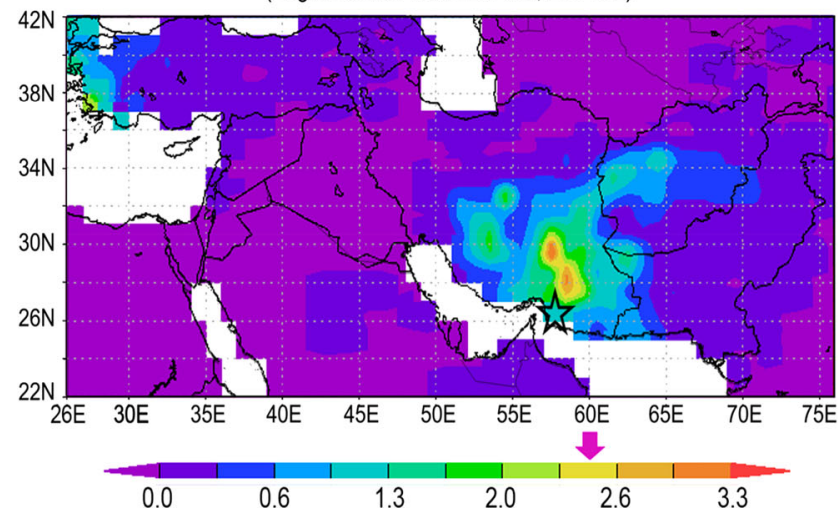

Fig. $5500 \mathrm{hPa}$ composite NCEP/NCAR reanalysis maps of a geopotential height mean, b geopotential height anomaly, c air temperature anomaly and d omega anomaly, and surface NASA/Giovanni

the earthquake events. The following Bushehr, Saravan and Angohran earthquake swarms were commenced within 3,9 and 33 days after the blocking-associated rainfall in their impressed epicenters. The aforementioned time delays between rainfall stress and seismicity support

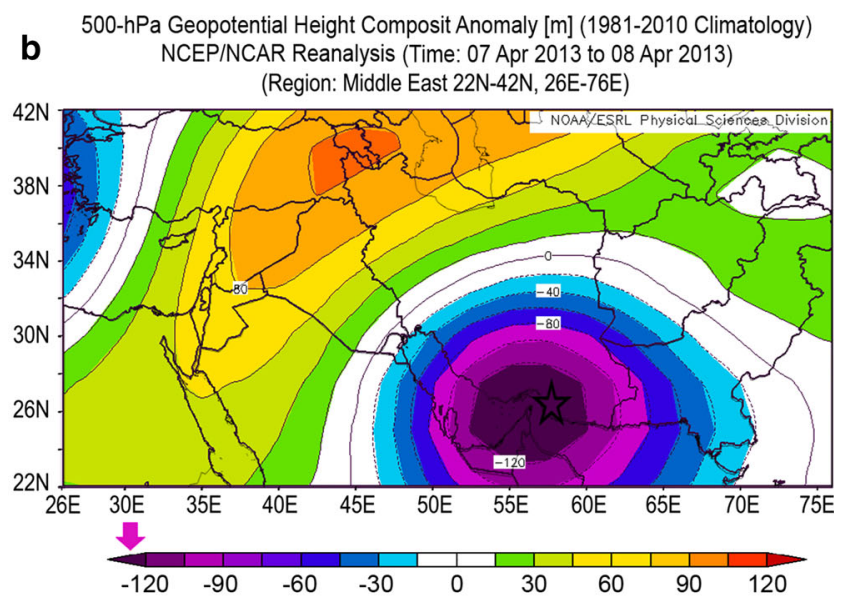

500-hPa Omega Composit Abonaly [Pa/s] (1981-2010 Climatology)
NCEP/NCAR Reanalysis (Time: $07 \mathrm{Apr} 2013$ to $08 \mathrm{Apr} 2013$ )

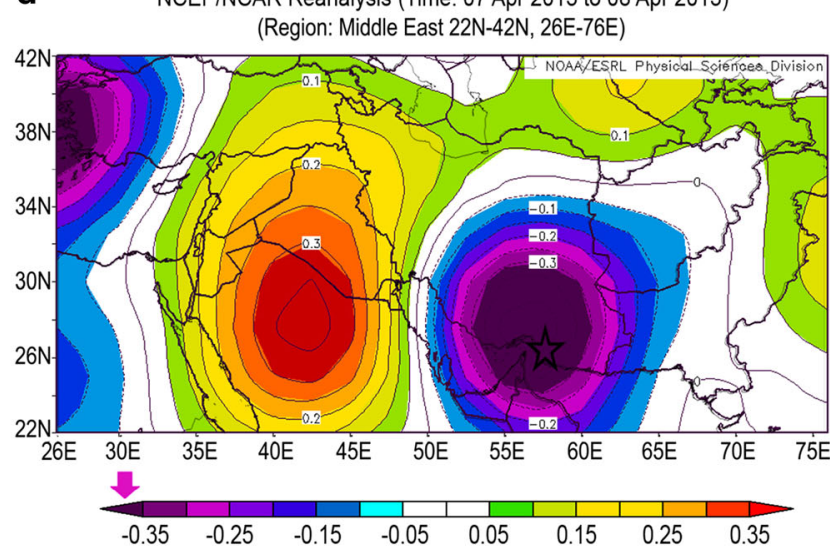

f GLDAS_CLM10SUBP_3H.001 Surface Latent Heat Flux [W/m^2] NASA/Giovanni Reanalysis (Time: 07 Apr 2013 to 08 Apr 2013) (Region: Middle East 22N-42N, 26E-76E)

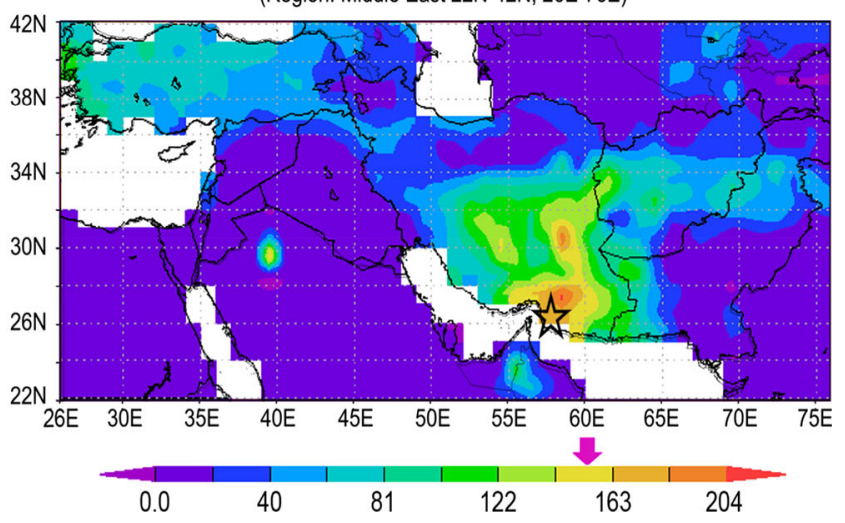

reanalysis maps of e rainfall rate and $\mathbf{f}$ latent heat flux during April 7-8, 2013 upon the Angohran epicenter

a geological mechanism of pore pressure changes (Wang and Manga 2009). The crustal structure and geology determines the arrival time delays in both deep and shallower hypocenters (Ma 2010). In addition, the teleseismic depth phase can be impressive on arrival time 

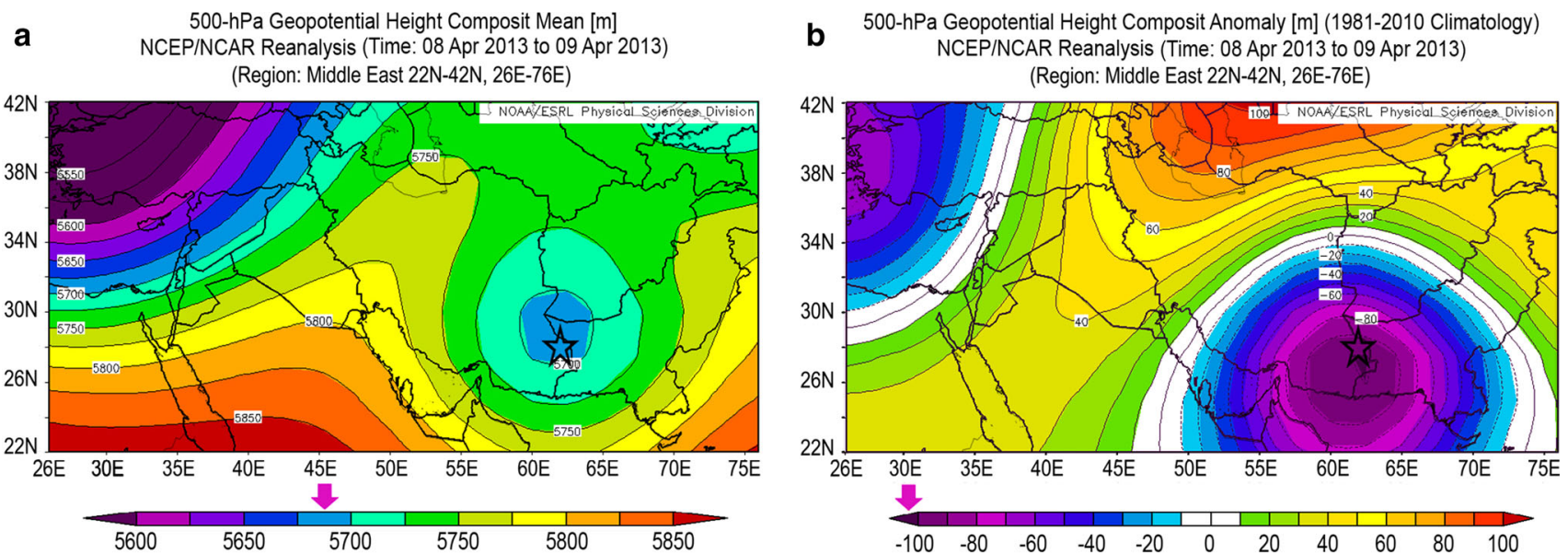

C $\quad 500-h P a$ Air Temperature Composit Abonaly [K] (1981-2010 Climatology) NCEP/NCAR Reanalysis (Time: 08 Apr 2013 to 09 Apr 2013) (Region: Middle East 22N-42N, 26E-76E)

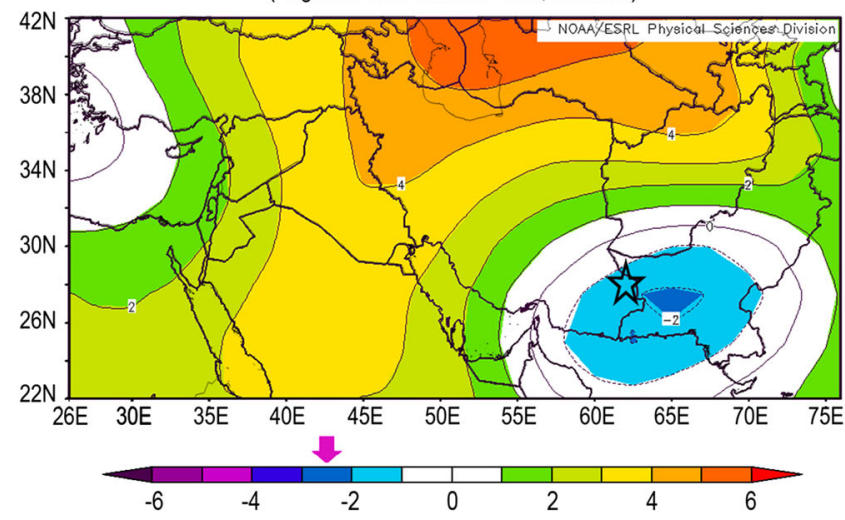

d 500-hPa Omega Composit Abonaly [Pa/s] (1981-2010 Climatology) NCEP/NCAR Reanalysis (Time: 08 Apr 2013 to 09 Apr 2013) (Region: Middle East 22N-42N, 26E-76E)

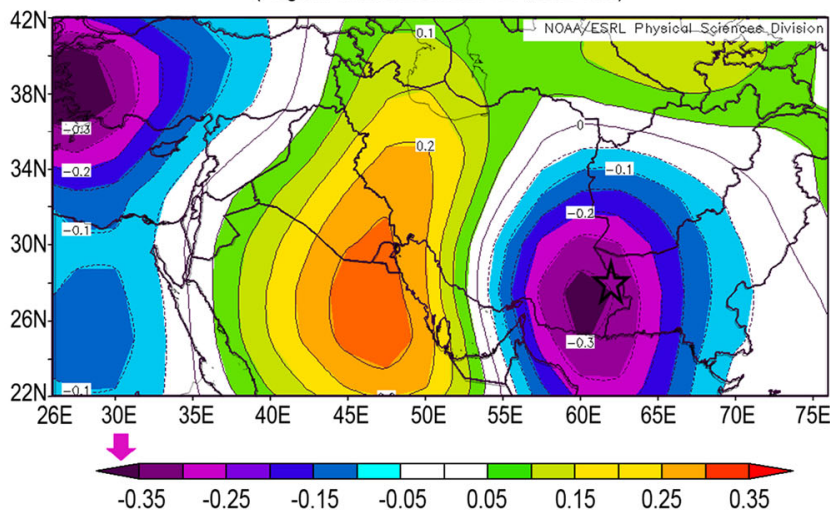

e GLDAS_CLM10SUBP 3 H.001 Rainfall Rate $\left[\left(10^{\wedge}-4\right) \mathrm{kg} / \mathrm{m}^{\wedge} 2 / \mathrm{s}\right]$ NASA/Giovanni Reanalysis (Time: 08 Apr 2013 to 09 Apr 2013) (Region: Middle East 22N-42N, 26E-76E)

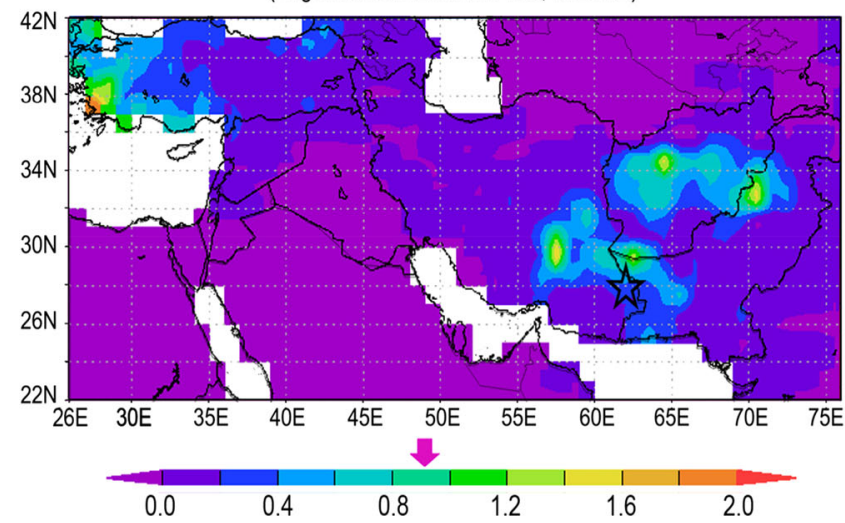

Fig. $6500 \mathrm{hPa}$ composite NCEP/NCAR reanalysis maps of a geopotential height mean, b geopotential height anomaly, c air temperature anomaly and d omega anomaly, and surface NASA/Giovanni

delays in geological zones (Goldstein and Dodge 1999). The various geological setting of the investigated epicenter locations in this study from Zagros sedimentary basin to Makran subduction zone can be influenced to

arrival time delays rainfall stress and seismicity. However, we can conclude that a model in which rainfall triggers the stress on the earth's lithospheric crust and following feedbacks can be proposed. 

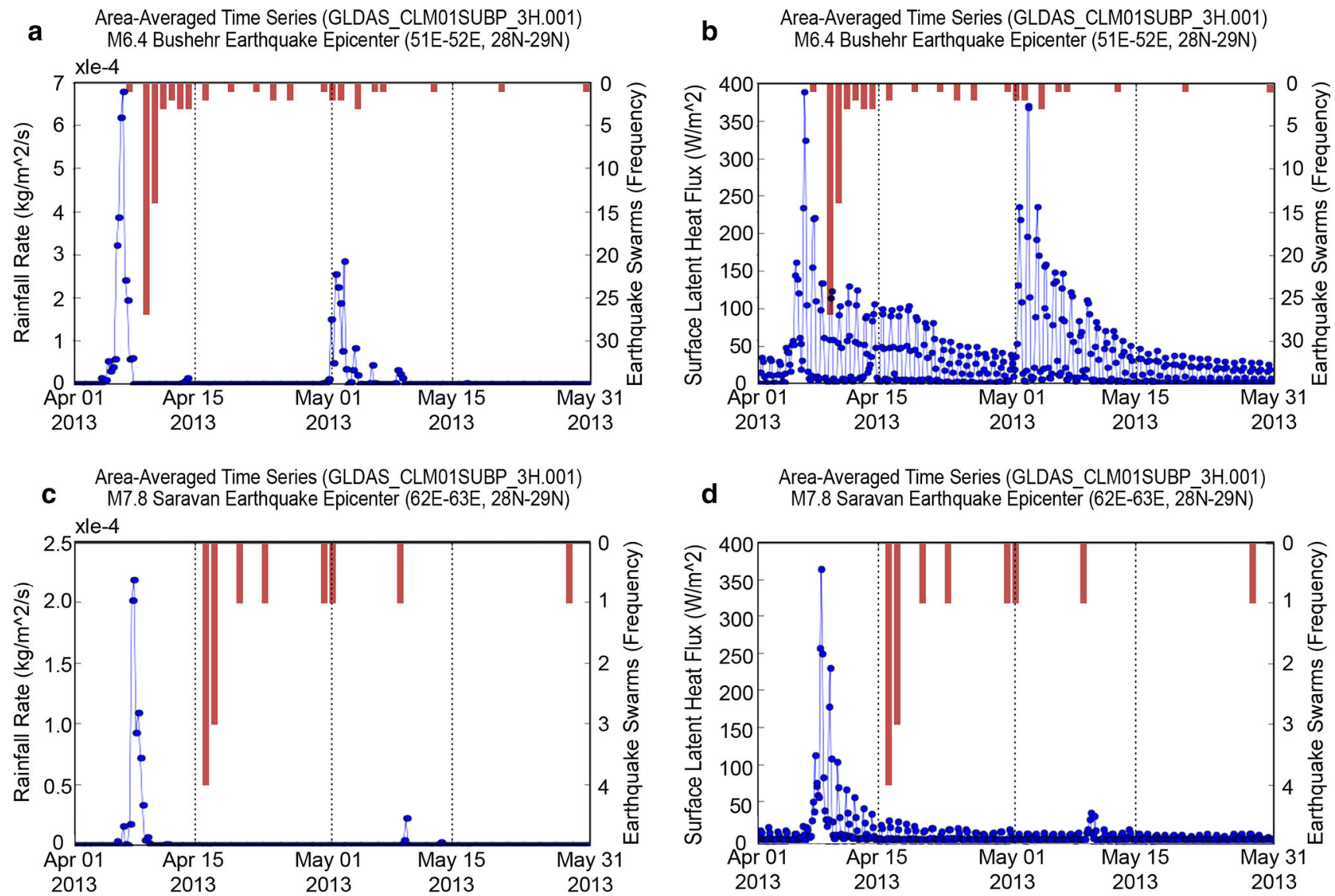

d Area-Averaged Time Series (GLDAS_CLM01SUBP $3 \mathrm{H} .001)$
M7.8 Saravan Earthquake Epicenter (62E-63E, 28N-29N)
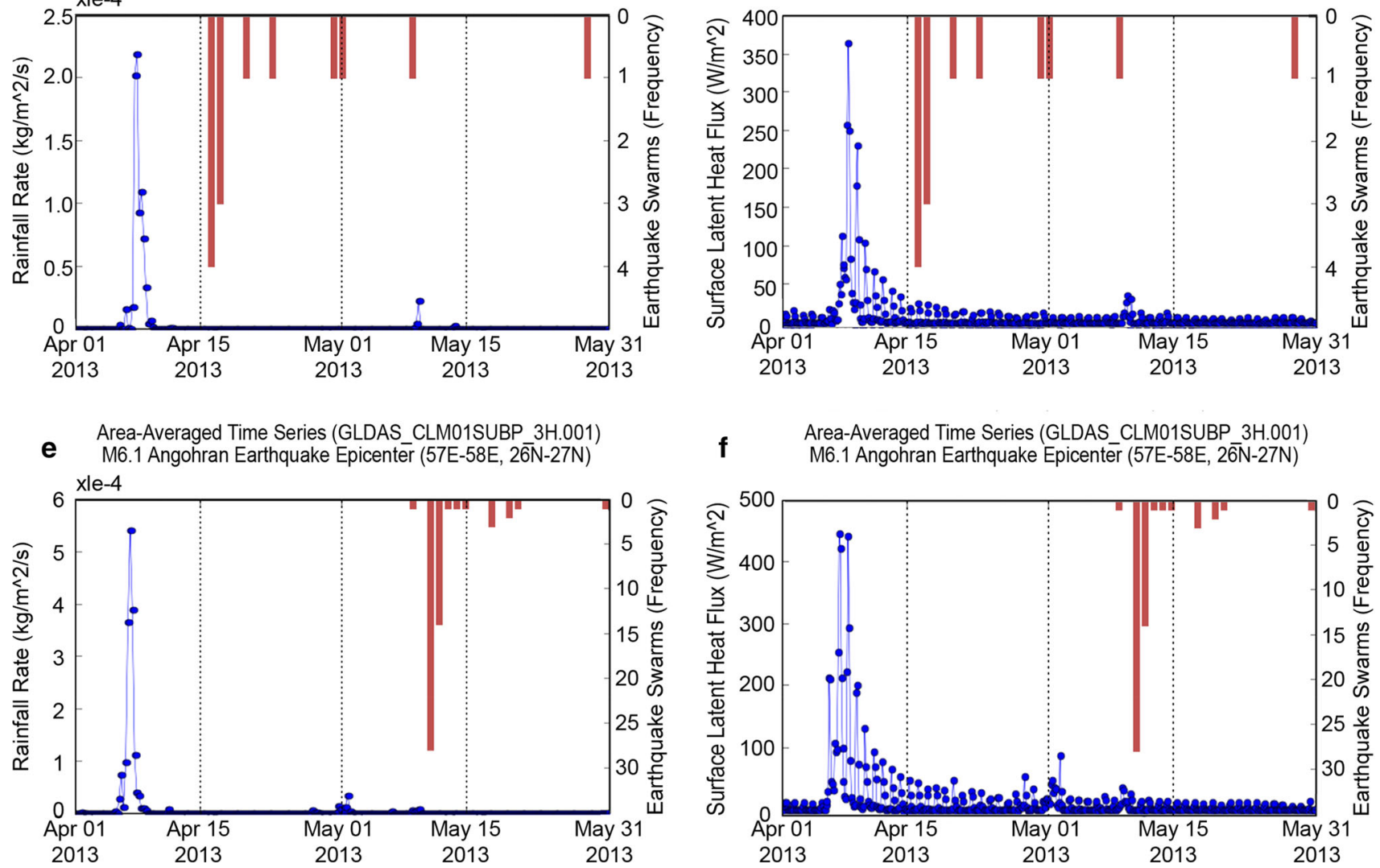

Fig. 7 Temporal data of rainfall rate and enhanced SLHF (NASA 2013) over the earthquake epicenters during April and May 2013 together with frequency of the earthquake swarms (USGS 2013), a, b Bushehr earthquake, c, d Angohran earthquake and e, f Saravan earthquake

A new climatic conceptual model in earthquake prediction

The recent developments of lithosphere-atmosphere-ionosphere coupling (LAIC) model as an interdisciplinary space-terrestrial framework (ISTF) is demonstrated by the observed anomalies within the preceding time before the seismic shock and exhibited some synergy in their behavior, space and time synchronism (Pulinets and $\mathrm{Ou}$ zounov 2011). The main advantage of the aforementioned model is the merger of the most of the observed phenomena before the earthquakes by physical mechanism. Nevertheless, the LAIC model has focused only on the fault activation and gas migration as the main source of precursor's chain without climatologic attitude. Now in the present study, we present a new climatic conceptual 
model. In this regard, we can claim that the atmospheric blocking-associated anomaly is the main triggering chain of lithospheric gas exhaustion, stress-induced seismicity and subsequent atmospheric anomalies. For this purpose, we observed a chain of lithospheric-atmospheric events, which occurred consecutively after a blocking event and before the earthquake swarms in the south parts of Iran. On this basis, the blocking event has reflected the largescale changes in the atmospheric condition such as the persistence of low pressure, trough formation, blockingassociated rainfall anomalies and extreme events. The rainfall event with the long persistency is considered as an extreme event (Nazaripour and Mansouri Daneshvar 2014). The blocking events have a significant correlation with the deepening rate of the preceding upstream troughs (Wiedenmann et al. 2002) and prevailing of the storm tracks (Schwierz et al. 2004). Hence, after the onset of a blocking, the intensification of blocking-associated rainfall rate occurred on the eastern flank of trough over southern Iran. Previously, blocking-associated rainfall was observed in the 2010 Pakistan extreme and anomalous rainfall (Hong et al. 2011). Blocking-associated rainfall with the largest significant anomalies usually happens to the east of a blocking ridge (Marshall et al. 2013). In a blocking, the high-pressure condition tends to be maintained over of the ridge, and low pressure and storm tracks are generated in east of the trough with a fundamental effect on regional climates and rainfall events. Then, the seismological regions are affected by the rainfall-triggered stress, where the lithospheric natural gasses are exhausted from the tectonic fractures. The gas exhaustion from stressed seismic areas may include of radon $(\mathrm{Rn})$, noble gases (e.g., $\mathrm{He}, \mathrm{Ne}$ and $\mathrm{Ar}$ ), and reaction gasses (e.g., $\mathrm{CO}_{2}, \mathrm{SO}_{2}$, and $\left.\mathrm{CH}_{4}\right)(\mathrm{Hsu}$ et al. 2010) together with a localized greenhouse condition (Choudhury et al. 2006). The increased rainfall-triggered stresses may be related to earth's crust electromagnetic (EM) emissions (Pulinets 2011) and sub-surface degassing. Transient electric currents that flow in the Earth's crust with low-frequency electromagnetic emissions (Freund et al. 2006) can influence to geomagnetic reaction. This lithospheric reaction causes to several atmospheric anomalies such as air ionization, abnormal cloud hydration, greenhouse condition and latent heat release (Pulinets et al. 2009; Pulinets and Ouzounov 2011; Mansouri Daneshvar et al. 2014a), which influence on the anomalous SLHF and rainfall event. Anomalous fluxes of latent heat release are due to air ionization and water vapor condensation on ions (Pulinets 2011). Ionization increases air velocity and up-streaming airflows (Liperovsky et al. 2005). Likewise, in recent theories, it have been proposed that the climate abnormal change is caused by the terrestrial heat exhaust of the earth's crust (Mu and
Mu 2013), which can be categorized as a reaction of lithospheric heat insulation against the external stresses. The matter and energy transferred from the earth's crust to atmosphere ceaselessly influences atmospheric processes (Mu and $\mathrm{Mu}$ 2013). This lithospheric reaction provides the way to reach the main precursors of upcoming earthquakes in the seismological regions. Therefore, the aforementioned lithospheric reaction is a positive feedback, which eventuates to abnormal atmospheric instability such as air disturbance, cyclogenesis, thunderstorms and the persistence of low pressure in the equatorward region of the block. The aforementioned abnormal characteristics have directly synergic effects on genesis the low-geopotential heights through the dipole blocking patterns of split-flow and cut-off low blocks. These blocking types can be commenced after an atmospheric disturbance (McWilliams 1980; Verkley 1990). In any case, we can detect an atmospheric-lithospheric cycle as a climatic conceptual model, which describe the chain of blocking-associated rainfall, preceding rainfall-triggered seismic stress, cyclogenesis and subsequent stressinduced seismicity in the seismological regions. In this regard, we believe that when the atmospheric blocking together rainfall-induced stresses is causes of the fault motions then its associated anomalies could be the earthquake precursors before the main seismic shocks. The schematic presentation of this conceptual modeling is shown in Fig. 8. Comparing the model and case studies revealed that if has been occurred an atmospheric blocking and following abnormal rainfall and SLHF over the seismological regions of Iran, then we can predict a major earthquake $(M>6)$ and its seismic swarm within next 3-33 days along the active faults. The deductive generalization of this hypothesis is required the more inductive and experimental studies in other seismological

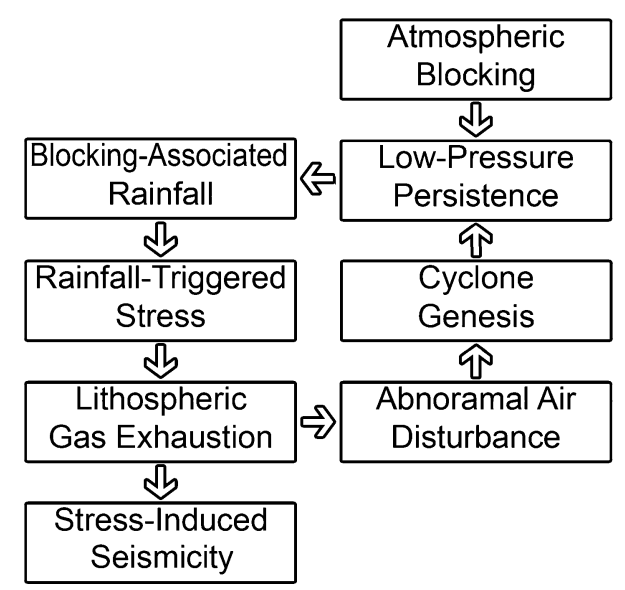

Fig. 8 The schematic presentation of the climatic conceptual model in earthquake prediction 
regions. Recently, an investigation of relationships between preceding atmospheric variations and 39 major earthquakes $(M>6)$ in Middle East has revealed that abnormal rainfall (about $+35 \mathrm{~mm}$ above the mean) and maximum values of SLHF (about $115 \mathrm{~W} \mathrm{~m}^{-2}$ ) occurred within 3-23 days prior to the main shock of earthquakes (Mansouri Daneshvar et al. 2014b). Hence, the presented conceptual model has utility as a predictive tool and can be applied to all seismological regions in the Middle East within less lag time.

\section{Conclusion}

The essence of block formation can be described as a largescale region of high pressure with low-potential vorticity, which extends poleward over a large-amplitude slowmoving cyclone (Pelly and Hoskins 2003). Previously, some researchers have examined the intensity of the upstream cyclogenesis, which dynamically associates with the formation and maintenance of blocking events (e.g., Konrad and Colucci 1988; Tsou and Smith 1990; Lupo and Smith 1995; Lupo 1997). In the present study, we observed that the seismological region in southern Iran experienced a deep cyclone during April 2013. Then, the deep trough caused enhanced extreme rainfall and anomalies of geopotential height, vertical velocity and latent heat flux over the epicenter locations. Hence, we concluded that a significant blocking episode during the early days of April 2013. The core of our study was to show the feedback mechanism of the aforementioned blocking effects on associated rainfall and following rainfall-triggered seismicity over the seismological regions. We finally presented a new climatic conceptual model. In this regard, we claimed that the atmospheric blocking-associated anomaly is the main triggering mechanism of lithospheric gas exhaustion, stress-induced seismicity and subsequent atmospheric anomalies. These reactions are tracked along a systematic feedback mechanism between atmosphere and lithosphere.

Acknowledgments We wish to acknowledge the NASA/Giovanni and NOAA/NCEP on web data-centers for transmission of reanalysis data. We are very grateful to four anonymous reviewers for their technical recommendations and practical interpretations. We like to thank Mrs. Somayeh Rezayi for data preparation.

\section{References}

Barriopedro D, Garcia-Herrera R, Lupo AR, Hernandez E (2006) A climatology of northern hemisphere blocking. J Clim 19(6):1042-1063
Buehler T, Raible CC, Stocker TF (2011) The relationship of winter season North Atlantic blocking frequencies to extreme cold or dry spells in the ERA-40. Tellus 63(2):212-222

Cattiaux J, Vautard R, Cassou C, Yiou P, Masson-Delmotte V, Codron F (2010) Winter 2010 in Europe: a cold extreme in a warming climate. Geophys Res Lett. doi:10.1029/ 2010GL044613

Choudhury S, Dasgupta S, Saraf AK, Panda S (2006) Remote sensing observations of pre-earthquake thermal anomalies in Iran. Int $\mathrm{J}$ Remote Sens 27(20):4381-4396

Costain JK, Bollinger GA, Speer JA (1987) Hydroseismicity: a hypothesis for the role of water in the generation of intraplate seismicity. Geology 15(7):618-621

Dole RM, Gordon ND (1983) Persistent anomalies of the extratropical Northern Hemisphere wintertime circulation. Geographical distribution and regional persistence characteristics. Mon Weather Rev 111(8):1567-1586

Dole R, Hoerling M, Perlwitz J, Eischeid J, Pegion P, Zhang T, Quan $\mathrm{XW}, \mathrm{Xu}$ T, Murray D (2011) Was there a basis for anticipating the 2010 Russian heat wave? Geophys Res Lett. doi:10.1029/ 2010GL046582

EMSC (2013) Scientific data of major earthquakes. EuropeanMediterranean Seismological Centre. http://www.emsc-csem. org/Earthquake

Freund FT (2003) Rocks that crackle and sparkle and glow: strange pre-earthquake phenomena. J Sci Explor 17(1):37-71

Freund FT, Takeuchi A, Lau BW (2006) Electric currents streaming out of stressed igneous rocks: a step towards understanding preearthquake low frequency EM emissions. Phys Chem Earth 31(4-9):389-396

Goldstein P, Dodge D (1999) Fast and accurate depth and source mechanism estimation using P-waveform modeling: a tool for special event analysis, event screening, and regional calibration. Geophys Res Lett 26(16):2569-2572

Gousheva MN, Glavcheva RP, Danov DL, Hristov PL, Kirov BB, Georgieva KY (2008) Electric field and ion density anomalies in the mid latitude ionosphere: possible connection with earthquakes? Adv Space Res 42(1):206-212

Hainzl S, Kraft T, Wassermann J, Igel H, Schmedes E (2006) Evidence for rainfall-triggered earthquake activity. Geophys Res Lett. doi:10.1029/2006GL027642

Hong CC, Hsu HH, Lin NH, Chiu H (2011) Roles of European blocking and tropical extratropical 2 interaction in the 2010 Pakistan flooding. Geophys Res Lett. doi:10.1029/ 2011GL047583

Hsu SC, Huang YT, Huang JC, Tu JY, Engling G, Lin CY, Lin FJ, Huang CH (2010) Evaluating real-time air-quality data as earthquake indicator. Sci Total Environ 408(11):2299-2304

Huang F, Zhou F, England MH (2004) Atmospheric circulation associated with anomalous variations in north Pacific wintertime blocking. Mon Weather Rev 132(5):1049-1064

Husen S, Bachmann C, Diardini D (2007) Locally triggered seismicity in the central Swiss Alps following the large rainfall event of August 2005. Geophys J Int 171(3):1126-1134

Iaffaldano G, Husson L, Bunge HP (2011) Monsoon speeds up Indian plate motion. Earth Planet Sci Lett 304:503-510

Jiménez MJ, Garćia-Fernández M (2000) Occurrence of shallow earthquakes following periods of intense rainfall in Tenerife, Canary Islands. J Volcanol Geotherm Res 103(1-4): 463-468

Konrad CE, Colucci SJ (1988) Synoptic climatology of 500-mb circulation changes during explosive cyclogenesis. Mon Weather Rev 116(7):1431-1443 
Kraft T, Wassermann J, Schmedes E, Igel H (2006) Meteorological triggering of earthquake swarms at Mt. Hochstaufen, SEGermany. Tectonophysics 424(3-4):245-258

Lejenäs H, Økland H (1983) Characteristics of Northern Hemisphere blocking as determined from a long time series of observational data. Tellus 35A(5):350-362

Liperovsky VA, Meister CV, Liperovskaya EV, Davidov VF, Bogdanov VV (2005) On the possible influence of radon and aerosol injection on the atmosphere and ionosphere before earthquakes. Nat Hazards Earth Syst Sci 5(6):783-789

Liu JY, Chuo YJ, Shan SJ, Tsai YB, Chen YI, Pulinets SA, Yu SB (2004) Pre-earthquake ionospheric anomalies registered by continuous GPS TEC measurements. Ann Geophys 22:1585-1593

Lupo AR (1997) A diagnosis of two blocking events that occurred simultaneously over the midlatitude Northern Hemisphere. Mon Weather Rev 125(8):1801-1823

Lupo AR, Smith PJ (1995) Climatological features of blocking anticyclones in the Northern Hemisphere. Tellus 47A(4):439-456

Ma S (2010) Focal depth determination for moderate and small earthquakes by modeling regional depth phases $\mathrm{sPg}, \mathrm{sPmP}$, and sPn. Bull Seismol Soc Am 100(3):1073-1088

Mansouri Daneshvar MR, Tavousi T, Khosravi M (2014a) Synoptic detection of the short-term atmospheric precursors prior to a major earthquake in the Middle East, North Saravan M 7.8 earthquake, SE Iran. Air Qual Atmos Health 7(1):29-39

Mansouri Daneshvar MR, Khosravi M, Tavousi T (2014b) Seismic triggering of atmospheric variables prior to the major earthquakes in the Middle East within a 12-year time-period of 2002-2013. Nat Hazards 74(3):1539-1553

Marshall AG, Hudson D, Hendon HH, Pook MJ, Alves O, Wheeler MC (2013) Simulation and prediction of blocking in the Australian region and its influence on intra-seasonal rainfall in POAMA-2. Clim Dyn 42(11-12):3271-3288

Mason BG, Pyle DM, Dade WB, Jupp T (2004) Seasonality of volcanic eruptions. J Geophys Res Solid Earth. doi:10.1029/ 2002JB002293

Mastin L (1994) Explosive tephra emissions at Mount St. Helens, 1989-1991: the violent escape of magmatic gas following storms. Geol Soc Am Bull 106:175-185

Matthews AJ, Barclay J, Carn S, Thompson G, Alexander J, Herd R, Williams C (2002) Rainfall-induced volcanic activity on Montserrat. Geophys Res Lett. doi:10.1029/2002GL014863

Matthews AJ, Barclay J, Johnstone JE (2009) The fast response of volcano-seismic activity to intense precipitation: triggering of primary volcanic activity by rainfall at Soufrière Hills Volcano, Montserrat. J Volcanol Geoth Res 184(3):405-415

McWilliams JC (1980) An application of equivalent modons to atmospheric blocking. Dyn Atmos Oceans 5(1):43-66

Miller SA (2008) Note on rain-triggered earthquakes and their dependence on karst geology. Geophys J Int 173(1):334-338

Mu Y, Mu X (2013) Energy conservation in the Earth's crust and climate change. J Air Waste Manag Assoc 63(2):150-160

Muço B (2013) The atmospheric water as a triggering factor for earthquakes in the central Virginia seismic zone. Nat Hazards. doi:10.1007/s11069-013-0902-9

Nazaripour H, Mansouri Daneshvar MR (2014) Spatial contribution of one-day precipitations variability to rainy days and rainfall amounts in Iran. Int J Environ Sci Technol 11(6):1751-1758

Neuberg J (2000) External modulation of volcanic activity. Geophys J Int 142(1):232-240
Ogasawara H, Kuwabara Y, Miwa T, Fujimore K, Hirano N, Koizumi M (2002) Post-seismic effects of an M 7.2 earthquake and microseismicity in an abandoned, flooded, deep mine. Pure Appl Geophys 159(1-3):63-90

Ondoh T (2009) Investigation of precursory phenomena in the ionosphere, atmosphere and groundwater before large earthquakes of $M>6.5$. Adv Space Res 43(2):214-223

Pelly JL, Hoskins BJ (2003) A new perspective on blocking. J Atmos Sci 60(5):743-755

Pulinets SA (2006) Space technologies for short-term earthquake warning. Adv Space Res 37(4):643-652

Pulinets SA (2011) The synergy of earthquake precursors. Earthq Sci 24(6):535-548

Pulinets SA, Ouzounov D (2011) Lithosphere-atmosphere-ionosphere coupling (LAIC) model: an unified concept for earthquake precursors validation. J Asian Earth Sci 41(4-5):371-382

Pulinets SA, Romanov AA, Urlichich YM, Romanov A Jr, Doda LN, Ouzounov D (2009) The first results of the pilot project on complex diagnosing earthquake precursors on Sakhalin. Geomagn Aeron 49(1):115-123

Pundhir D, Singh B, Singh OP (2014) Anomalous TEC variations associated with the strong Pakistan-Iran border region earthquake of 16 April 2013 at a low latitude station Agra, India. Adv Space Res 53(2):226-232

Rex DF (1950) Blocking action in the middle troposphere and its effects upon regional climate. II. The climatology of blocking action. Tellus 2(4):275-301

Scherrer SC, Croci-Maspoli M, Schwierz C, Appenzeller C (2006) Two-dimensional indices of atmospheric blocking and their statistical relationship with winter climate patterns in the EuroAtlantic region. Int J Climatol 26(2):233-249

Schwierz C, Croci-Maspoli M, Davies HC (2004) Perspicacious indicators of atmospheric blocking. Geophys Res Lett. doi:10. 1029/2003GL0193

Shapiro SA, Kummerow J, Dinske C, Asch G, Rothert E, Erzinger J, Kmpl HJ, Kind R (2006) Fluid induced seismicity guided by a continental fault: injection experiment of 2004/2005 at the German Deep Drilling Site (KTB). Geophys Res Lett. doi:10. 1029/2005GL024659

Sillmann J, Croci-Maspoli M (2009) Present and future atmospheric blocking and its impact on European mean and extreme climate. Geophys Res Lett. doi:10.1029/2009GL038259

Sillmann J, Croci-Maspoli M, Kallache M, Katz RW (2011) Extreme cold winter temperatures in Europe under the influence of north Atlantic atmospheric blocking. J Clim 24(22):5899-5913

Tadokoro K, Ando M, Nishigami K (2000) Induced earthquakes accompanying the water injection experiment at the Nojima fault zone, Japan: seismicity and its migration. J Geophys Res Solid Earth 105(B3):6089-6104

Tibaldi S, Molteni F (1990) On the operational predictability of blocking. Tellus 42A(3):343-365

Trigo R, Trigo I, DaCamara C, Osborn TJ (2004) Climate impact of the European winter blocking episodes from the NCEP/NCAR reanalyses. Clim Dyn 23(1):17-28

Tsou CH, Smith PJ (1990) The role of synoptic/planetary scale interactions during the development of a blocking anticyclone. Tellus 42A(1):174-193

USGS (2013) Technical reports of significant earthquakes. United States Geological Survey. http://earthquake.usgs.gov/ earthquakes

Verkley WTM (1990) Modons with uniform absolute vorticity. J Atmos Sci 47(6):727-745 
Violette S, de Marsily G, Carbonnel JP, Goblet P, Ledoux E, Tijani SM, Vouille G (2001) Can rainfall trigger volcanic eruptions? A mechanical stress model of an active volcano: 'Piton de la Fournaise', Reunion Island. Terra Nova 13(1):18-24

Wang CY, Manga M (2009) Earthquakes influenced by water. In: Wang CY, Manga M (eds) Earthquake and water, Chap 8. Springer, Berlin, pp 125-139
Wiedenmann JM, Lupo AR, Mokhov II, Tikhonova EA (2002) The climatology of blocking anticyclones for the northern and southern hemispheres: block intensity as a diagnostic. J Clim 15(23):3459-3473 